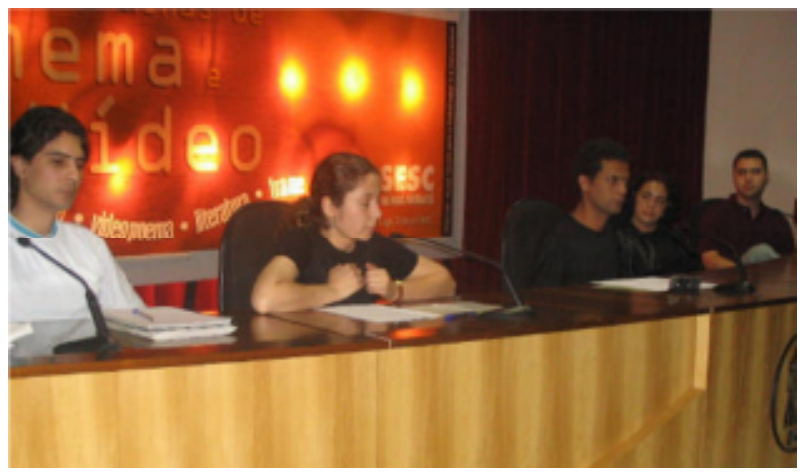

\title{
Sentimos a necessidade de criar um projeto específico para o incentivo da leitura
}

\author{
Janice Fortini \\ por Kênia Aulízia Herédia
}

Janice Fortini é Gerente do SESC-LACES-JK (Liceu de Artes, Cultura, Esporte e Saúde Juscelino Kubitscheck) e responsável por uma importante parceria do SESC-MG com o Programa A tela e o texto na realização das Mostras Minas de Cinema e Vídeo de 2003 e 2004.

Kênia Aulízia Herédia é membro da coordenação coletiva do Programa $A$ tela e o texto, Mestre em Teoria da Literatura (FALE/UFMG) e professora da rede municipal de Belo Horizonte.

Kênia Aulízia Herédia - O LACES-JK está estrategicamente localizado na região central de Belo Horizonte. Qual é o público das atividades e dos eventos realizados nesse espaço? A senhora poderia falar um pouco sobre os programas culturais mantidos pelo LACES-JK?

Janice Fortini - Kênia, eu gostaria de falar um pouco da história do prédio, pois o processo de restauração dele pressupõe não só a reconstituição da construção e a valorização do patrimônio histórico e cultural, mas também o resgate de sua utilização social.

O prédio que hoje abriga o SESC-LACES/JK, na Rua dos Caetés esquina de Rua São Paulo, ajuda a escrever a história de Belo Horizonte há quase 80 anos. Hoje, restaurado pelo SESC/MG, ele está resgatando a memória da cidade e valorizando seu patrimônio cultural.

o prédio foi inaugurado em 1928, em uma época em que Belo Horizonte vivia seu momento de núcleo urbano moderno. Mas com o rápido crescimento da cidade, os problemas sociais começaram a surgir. Experimentamos o esvaziamento do centro em função da perda da 
segurança que tanto tentamos agora resgatar. 0 processo de restauração deste prédio pressupõe não só a reconstituição da construção e a valorização do patrimônio histórico e cultural, mas também o resgate de sua utilização social.

Hoje, Belo Horizonte vive um momento de mobilização das principais lideranças que buscam pensar o hipercentro como local agradável de se viver, de transitar, de desfrutar de lazer e cultura. Neste contexto, O SESC/MG transforma este prédio em sua mais nova unidade: - LACES/JK, que abriga a Biblioteca Central, dois auditórios, salas de cursos, área de saúde e esportes. Assim, o LACES/JK é um espaço no centro de Belo Horizonte visualizado pelo SESC/MG como espaço para promover a integração de arte, cultura, esporte e saúde, para intermediar o conhecimento e facilitar $\circ$ acesso à cultura, contribuindo, assim, para o fortalecimento da cidadania não só de seus associados, mas também de toda a comunidade belorizontina.

O LACES/JK vem, progressivamente, resgatando a identidade cultural do centro da cidade, facilitando o acesso à cultura para as várias camadas da sociedade, principalmente para estudantes, para pessoas que buscam programação cultural de qualidade e que trabalham no entorno do prédio ou que buscam os serviços prestados pelo SESC/MG; - qual abre as portas do LACES/JK à comunidade belorizontina, sem fazer distinção entre o intelectual atento às regras e disciplinas do fazer e o espectador das coisas simples.

Dentre suas várias realizações, que compreendem iniciativas de promoção, difusão e incentivo cultural, como exposições, mostras, oficinas, cursos, seminários e espetáculos realizados por este LACES/JK, destacamos o Projeto ponto de encontro - literatura e arte e a Mostra Minas de cinema e vídeo.

Atualmente, a senhora gerencia as atividades dessa unidade do SESC e, há algum tempo, administrou a biblioteca. A partir dessa experiência, como a senhora avalia a questão da leitura? Como é a participação do público nos eventos e programas dedicados à divulgação da leitura? As pessoas têm freqüentado a biblioteca? Elas levam livros para casa?

A Biblioteca Central integra o LACES/JK, ocupando os dois primeiros andares do prédio e tendo freqüência média diária de 500 pessoas. As bibliotecas do SESC constituem um acervo diversificado e permanentemente atualizado, com cerca de 180.000 volumes distribuidos entre a Biblioteca Central, as 20 sucursais no interior, na capital e nas três unidades-volantes, que levam a cultura às mais distantes cidades do Estado. 
Além de prestar os serviços de pesquisas, acesso à Internet, leitura de periódicos, empréstimo de livros e de fitas de vídeo, a Biblioteca Central também desenvolve projetos na área de educação e cultura, como:

* Banco de troca de livros, que facilita o acesso ao livro didático;

* Mostra de inovações pedagógicas em Língua Portuguesa, com o objetivo de estimular a pesquisa e a inovação pedagógica nas escolas, valorizando o educador e o seu comprometimento com uma educação de qualidade e assim contribuindo com o processo educacional;

* Projeto interagindo e transformando, que visa dar subsídios aos educadores para a criação e a construção de novas alternativas em seu dia-a-dia, por meio de palestras e dinâmicas contribuindo com o processo educacional, transformando a sala de aula em um momento prazeroso de ensinamento e de aprendizagem;

* Projeto educação além dos muros que, conectando recursos e pessoas, leva, simultaneamente, a três escolas da rede pública, durante um ano, várias ações agrupadas nos módulos: recreação, alimentação (com implantação de horta escolar), saúde e higiene, oficinas artesanais e atividades culturais, com o objetivo de promover uma revitalização da comunidade escolar, valorizando a escola, o professor, o aluno e sua família.

Sentimos a necessidade de criar um projeto específico para incentivo à leitura, pois observamos o baixo índice de empréstimo dos livros nas bibliotecas-volantes que atendem às escolas públicas. Dessa forma, criamos o Projeto jovens leitores, que realiza um atendimento sistematizado nas escolas durante um ano, integrando as atividades da Unidade Volante de Biblioteca (caminhão-biblioteca) com oficinas de contação de histórias, visando transformar alunos da rede de ensino da Grande Belo Horizonte em contadores de histórias, utilizando a dramatização, dando vida aos textos, valorizando o livro e assim, formando leitores e disseminadores do gosto pela leitura.

Os livros trabalhados constam do acervo da Biblioteca-volante, como forma de explorar e valorizar o seu acervo. A Biblioteca-volante (com um acervo diversificado, que totaliza 7.000 livros) acompanha o trabalho desenvolvido em cada escola, disponibilizando para empréstimo todo o seu acervo aos alunos e também a toda a comunidade de cada região. Periodicamente são realizadas apresentações dos contadores de histórias em suas escolas e também entre as escolas participantes do projeto e em eventos realizados pelo SESC/MG, despertando o interesse de aprimoramento de cada grupo. 
Com o Projeto jovens leitores, O SESC/MG está promovendo a mobilização constante das escolas participantes e realizando uma ação efetiva de disseminação do gosto pela leitura. A Biblioteca Central do SESC/MG vem cumprindo sua missão de popularizar o acesso aos livros, incentivando o gosto pela leitura e colocando a cultura ao alcance de todos.

\begin{abstract}
Em 2003 e 2004 foram realizadas duas edições da Mostra Minas de cinema e vídeo, com a proposta de exibir e debater com o público uma produção audiovisual diversificada. Como tem sido essa experiência? Com base nos debates realizados, pode-se afirmar que o audiovisual realmente dificulta a leitura do texto impresso?
\end{abstract}

Na minha opinião, o audiovisual estimula a leitura do texto impresso e este nunca vai deixar de proporcionar um momento prazeroso de lazer. Podemos observar que quando uma história é adaptada para as telas e exibida em cinema ou televisão, imediatamente cresce o número de vendas do livro que a veicula. Os leitores sabem que no texto impresso encontramos maior nível de detalhamento e uma linguagem diferente e enriquecedora.

A I Mostra Minas de cinema e vídeo valorizou as produções de cineastas e videomakers contemporâneos do Estado e contou com a presença do Secretário de Estado da Cultura, Dr. Luiz Roberto Nascimento e Silva. A programação incluiu exibições de filmes, videopoemas e frames, sempre seguidas de mesas-redondas, com participação de renomados cineastas, videomakers e escritores mineiros. Em todos os dias o evento foi bastante prestigiado pelo público.

A II Mostra apresentou de forma integrada a discussão literária e a produção cinematográfica e videográfica atualmente desenvolvidas por universidades como PUC-Minas, UFMG, UEMG e pelo Programa BH Cidadania/PBH, contando com a participação de renomados acadêmicos na programação, mas não atingiu o mesmo público da primeira realização. Com a Mostra Minas de cinema e vídeo, o SESC/MG abriu espaço, num formato original em Belo Horizonte, para a reflexão das linguagens do cinema e do vídeo, voltadas tanto para iniciantes e interessados, quanto para profissionais da área.

Nessas Mostras, ressaltamos a valiosa parceria do Programa $A$ Tela e o Texto que, além de elaborar a programação das duas Mostras, contribuiu enriquecendo os debates em todas as mesasredondas. 